\title{
Reuna
}

\section{ANÁLISE DA RELAÇÃO ENTRE SUPORTE ORGANIZACIONAL PERCEBIDO, EXAUSTÃO E COMPROMETIMENTO ORGANIZACIONAL}

\section{ANALYSIS OF THE RELATIONSHIP BETWEEN PERCEIVED ORGANIZATIONAL SUPPORT, EXHAUSTION AND ORGANIZATIONAL COMMITMENT}

\author{
http://dx.doi.org/10.21714/2179-8834/2019v24n3p1-19
}

\author{
Harrison Bachion Ceribeli \\ Universidade Federal de Ouro Preto (UFOP), Brasil. \\ E-mail: harrisonbceribeli@hotmail.com \\ Rafaela Máximo Barbosa \\ Universidade Federal de Ouro Preto (UFOP), Brasil. \\ E-mail: rm-barbosa@hotmail.com
}

Submissão: 02 Fev. 2018 Publicação: 02 Nov. 2019. Sistema de avaliação: Double blind review. Centro Universitário UNA, Belo Horizonte - MG, Brasil. Editor geral: Prof. Dr. Gustavo Quiroga Souki

Este artigo encontra-se disponível nos seguintes endereços eletrônicos:

http://revistas.una.br/index.php/reuna/article/view/1011

http://dx.doi.org/10.21714/2179-8834/2019v24n3p1-19

\section{Resumo}

Esta pesquisa teve como objetivo analisar a influência que o suporte organizacional percebido exerce sobre o nível de exaustão emocional e o comprometimento organizacional dos trabalhadores. Realizou-se um levantamento de campo nas cidades de Mariana e Ouro Preto, Estado de Minas Gerais, Brasil. Para a análise de dados, foi utilizada a técnica de Modelagem de Equações Estruturais. Os resultados encontrados constataram que há uma relação negativa entre o suporte organizacional percebido e a exaustão do trabalhador, e uma relação positiva entre o suporte organizacional percebido e o comprometimento do trabalhador. Tais resultados evidenciam que as organizações que se preocupam com o bem-estar do funcionário contribuem para o aumento do compromisso e redução do esgotamento por ele demonstrados. Além disso, verificou-se uma relação positiva entre a exaustão e o comprometimento do trabalhador. Essa última relação foi explicada levantando-se a hipótese de que os indivíduos mais esgotados podem se apegar à organização, esperando que ela reconheça e recompense o seu esforço no futuro.

Palavras-chave: Esgotamento mental, Compromisso do trabalhador, Comportamento humano no trabalho. 


\section{Abstract}

This research aimed to analyze the influence that the perceived organizational support exerts on the level of emotional exhaustion and the organizational commitment of the workers. A survey was conducted in the cities of Mariana and Ouro Preto, State of Minas Gerais, Brazil. For the data analysis, the Structural Equation Modeling technique was used. The results showed that there is a negative relationship between perceived organizational support and worker exhaustion, and a positive relationship between perceived organizational support and worker commitment. These results show that organizations concerned with the well-being of their employees contribute to the increase of commitment and reduction of their exhaustion. In addition, a positive relationship between worker exhaustion and commitment was identified. This last relation was explained by proposing the hypothesis that the most exhausted individuals can become attached to the organization, hoping that it will recognize and reward its effort in the future.

Keywords: Mental exhaustion. Employee commitment. Human behavior at work.

\section{Introdução}

Tanto no meio empresarial quanto no acadêmico, a competitividade de uma organização já foi associada, de forma exclusivista, a seus ativos tangíveis; mais recentemente, contudo, o capital intelectual também passou a ser visto como fonte de vantagem competitiva (OLIVEIRA; LIMONGI-FRANÇA, 2005), sendo que foi a partir da década de 1980 que os gestores começaram a prestar mais atenção ao comportamento de seus colaboradores, movidos pela mudança de paradigma que promoveu a gestão de pessoas a um patamar estratégico (BIANCHI; QUISHIDA; FORONI, 2017).

$\mathrm{Na}$ atualidade, a ideia de que os funcionários "devem vestir a camisa da empresa" passou a ser questionada e gradualmente abandonada, considerando que enfatiza uma perspectiva unilateral de responsabilidade e não contempla a importância da reciprocidade na relação entre empregados e empregadores.

Com isso, ganhou destaque o suporte organizacional percebido, que se refere à percepção dos funcionários de que a relação com a empresa em que trabalham é pautada no compromisso mútuo, criando neles a expectativa de que o aumento de seu desempenho nas atividades laborais será notado e recompensado, e os levando, ao mesmo tempo, a se sentirem responsáveis por contribuir mais com seu empregador, o que tende a afetar positivamente os comportamentos assumidos no trabalho (KURTESSIS et al., 2017).

O suporte organizacional percebido tem sido associado na literatura, ainda que de forma exígua, a diferentes dimensões do comportamento humano dentro das organizações, como o comprometimento organizacional (KURTESSIS et al., 2017), que remete ao compromisso desenvolvido pelos indivíduos em relação à empresa onde trabalham (MEYER; ALLEN, 1991). De acordo com Osterman (2011), é importante que se obtenham elevados níveis de comprometimento dos funcionários, principalmente em mercados nos quais a qualidade e a satisfação do cliente são fundamentais para o sucesso dos negócios, tornando-se, portanto, necessário que 
sejam empreendidas estratégias para se estreitar o vínculo entre organização e colaboradores.

Outra dimensão associada ao suporte organizacional é a exaustão emocional, que pode ser definida como o esgotamento mental do sujeito, resultante do elevado estresse crônico no ambiente laboral, que causa prejuízos à saúde do trabalhador e ocasiona altos custos para a organização (TAMAYO, 2002), evidenciando-se que se trata de uma questão bastante relevante na contemporaneidade.

Partindo da importância dessas duas dimensões do comportamento humano no trabalho e da escassez de estudos investigando como ambas estão associadas à reciprocidade percebida pelos indivíduos em sua relação com seu empregador, definiu-se como objetivo de pesquisa analisar a influência que o suporte organizacional percebido exerce sobre o nível de exaustão emocional e o comprometimento organizacional dos trabalhadores.

A justificativa para esta pesquisa reside na existência de um número reduzido de pesquisas até então publicadas em torno da temática suporte organizacional percebido, o que impossibilita que se avance na compreensão de como esse construto afeta o trabalhador. Ademais, espera-se contribuir para reforçar a importância da reciprocidade na relação entre empregados e empregadores como ferramenta para se alcançar melhor desempenho organizacional (PASCHOAL; TORRES; PORTO, 2010).

\section{Referencial teórico}

\subsection{Exaustão no trabalho}

Atualmente, o número de profissionais afetados pela síndrome de Burnout ou do esgotamento profissional tem aumentado substancialmente, o que resulta em insatisfação e desmotivação no ambiente de trabalho, gerando um problema crescente para as organizações; por isso, o assunto tem despertado crescente interesse tanto em âmbito empresarial quanto científico (ROŽMAN et al., 2017).

A síndrome de Burnout é definida como um tipo de resposta prolongada para estresses crônicos emocionais e interpessoais no trabalho, composta por três dimensões: a exaustão emocional, que se refere ao esgotamento dos recursos emocionais do sujeito; a despersonalização, que está relacionada à indiferença e perda de idealismo; e, por fim, a redução da realização pessoal, que é uma diminuição do sentimento de competência e produtividade (MASLACH; GOLDBERG, 1998).

A exaustão emocional, que é um dos objetos de estudo desta pesquisa, é apontada como o primeiro grupo de sintomas do esgotamento profissional ou Burnout a se manifestar (CORDES; DOUGHERTY, 1993), e resulta, dentre outros fatores, da incapacidade do supervisor de ouvir seus subordinados, o que indica que a ausência de escuta ativa por parte dos líderes da organização influência direta e negativamente o bem-estar dos liderados (LLOYD et al., 2015).

De forma complementar, no estudo de Wheeler, Halbesleben e Whitman (2013), constatou-se que comportamentos abusivos por parte da chefia também tendem a levar à exaustão dos funcionários, que passam, por sua vez, a apresentar comportamentos dessa mesma natureza diante dos colegas de trabalho. Nesta REUNA, Belo Horizonte - MG, Brasil, v.24, п.3, p. I-19, Jul. - Set. 2019 - ISSN 2179-8834 
mesma linha, Chi e Liang (2013) concluíram que os indivíduos são passíveis de experimentar elevados índices de exaustão emocional quando são alvos de comportamentos hostis por parte de seus supervisores no ambiente laboral; logo, a exaustão pode ocorrer devido ao desequilíbrio entre as exigências emocionais decorrentes da supervisão abusiva e os recursos individuais disponíveis para lidar com tais situações.

Corroborando os estudos supramencionados, Schermuly e Meyer (2016) concluíram que tanto o empoderamento dos indivíduos quanto a depressão e a exaustão no ambiente laboral são estados de ordem psicológica associados à qualidade da convivência entre supervisores e subordinados em uma organização, revelando que as relações entre ambos influenciam a cognição relacionada ao trabalho e a saúde mental dos trabalhadores.

Todavia, existem outros fatores, além da qualidade da supervisão, que levam ao esgotamento emocional dos funcionários de uma organização, tais como as políticas e práticas de gestão de pessoas adotadas (SHANTZ et al., 2016; PAIVA et al., 2016).

Práticas que dão suporte ao desenvolvimento dos trabalhadores ao longo do tempo tendem a levá-los a se envolverem mais com o trabalho e a apresentarem menores níveis de exaustão emocional; em contrapartida, quando a área de Recursos Humanos tem como objetivo exclusivo reduzir custos, os funcionários normalmente sofrem com níveis mais elevados de exaustão (SHANTZ et al., 2016).

Ademais, organizações que não possuem uma política voltada para a valorização de seus funcionários, o que inclui oportunidades de ascensão e autonomia para realizar tarefas, e que não ofertam um local de trabalho adequado podem contribuir para o esgotamento emocional dos mesmos (PAIVA et al., 2016).

Em compensação, em organizações nas quais são oferecidas maiores oportunidades de crescimento profissional para os funcionários e são realizados investimentos que influenciam positivamente sua empregabilidade, o desgaste emocional dos indivíduos tende a ser menor, enquanto a identificação organizacional tende a aumentar (LU; SUN; DU, 2016).

Além da qualidade da supervisão e das políticas e práticas organizacionais, podem ser apontados como antecedentes que levam à exaustão dos profissionais a sobrecarga de trabalho e os conflitos entre o trabalho e a família, ou seja, indivíduos que possuem elevada carga de atividades e/ou que não conseguem separar seus papeis no trabalho e na família apresentam maior esgotamento emocional e, em consequência disso, ficam mais distantes no ambiente laboral, exibindo um desempenho insatisfatório na execução de suas tarefas na organização (KARATEPE, 2013).

Contudo, além de impactar de forma negativa a produtividade e desempenho individuais, a exaustão dos funcionários pode levar também ao aumento da rotatividade na organização, o que evidencia a necessidade de se implantarem medidas para redução do estresse no trabalho, criando uma cultura de gerenciamento dos fatores estressores no ambiente laboral (CHO; CHOI; LEE, 2014). 
Neste sentido, partindo da premissa de que a exaustão afeta o comportamento e as atitudes do indivíduo no trabalho, definiu-se a primeira hipótese da pesquisa:

H1: A exaustão emocional dos profissionais influencia negativamente o comprometimento organizacional.

É importante destacar que, além dos efeitos negativos que a exaustão emocional traz às organizações, há também consequências perniciosas para os trabalhadores, que têm sua saúde afetada e a qualidade de suas relações interpessoais prejudicada, especialmente no que se refere ao convívio familiar, podendo, em casos mais graves, acarretar em depressão e distúrbios diversos (TAMAYO, 2002).

Por isso, é importante combatê-la e mitigá-la, o que pode ser feito utilizando-se dois tipos de abordagens: intervenção e prevenção, sendo a primeira voltada para o indivíduo que já apresenta sintomas, enquanto a segunda tem como objetivo impedir o desenvolvimento da exaustão no ambiente laboral (TAMAYO, 2002).

\subsection{Comprometimento organizacional}

Os estudos abordando o comprometimento organizacional tiveram início na segunda metade da década de 1970 e se expandiram no decorrer do decênio seguinte, o que levou à publicação de um número substancial de pesquisas sobre o tema, principalmente em âmbito internacional (BORGES-ANDRADE, 1994).

O comprometimento do funcionário, que remete ao compromisso e fidelidade apresentados por ele em relação à organização onde trabalha, influencia, no dia a dia, suas ações e atitudes no ambiente laboral, o que inclui, por exemplo, a prontidão com que atende as demandas organizacionais (SILVA; VIEIRA; RODRIGUES, 2014).

Meyer e Allen (1991), partindo da perspectiva de que o comprometimento é um estado psicológico que reflete o relacionamento do funcionário com a organização e que tem implicações em sua decisão de permanecer ou não no emprego, propuseram um modelo conceitual desmembrando o construto em três dimensões: a afetiva, a instrumental e a normativa.

O comprometimento afetivo refere-se a um vínculo emocional do empregado em relação a seu empregador, que nasce a partir da identificação individual com a organização e da satisfação experimentada por fazer parte dela, levando à decisão de permanecer no emprego; por sua vez, o comprometimento instrumental resulta da reflexão que o trabalhador faz a respeito dos custos ou perdas relacionadas com sua possível saída do emprego; por fim, o comprometimento normativo remete a um sentimento de obrigação que leva o sujeito a permanecer vinculado à organização (MEYER; ALLEN, 1991; WIJNMAALEN; HEYSE; VOORDIJK, 2016).

Sendo assim, pode-se afirmar que os empregados que são movidos pelo compromisso afetivo permanecem na organização porque querem; os que desenvolvem o compromisso instrumental permanecem porque precisam; e aqueles 
que experimentam maior nível de compromisso normativo continuam no mesmo emprego porque se sentem obrigados (MEYER; ALLEN; SMITH, 1993).

O modelo de Meyer e Allen é o mais utilizado na literatura para a definição das dimensões do comprometimento organizacional. Entretanto, em seu trabalho, Rodrigues e Bastos (2010) sugerem a exclusão da dimensão instrumental, pois argumentam que o construto não deve estar associado à análise individual acerca das possíveis perdas ao sair do emprego. Ainda segundo os mesmos autores, a dimensão instrumental associa-se com a continuidade do colaborador na organização, mas não com seu comprometimento.

A importância do comprometimento reside em dois aspectos: primeiro, o desempenho da organização depende do compromisso de seus profissionais com a missão, valores e objetivos organizacionais; em segundo lugar, o compromisso demonstrado pelos funcionários aumenta a possibilidade de a organização implantar mudanças de forma bem-sucedida e enfrentar momentos de instabilidades com sucesso (BRITO; BASTOS, 2001).

Neste sentido, considerando que o desempenho da organização está atrelado ao compromisso de seus funcionários, é importante que sejam implantadas práticas para incentivar o comprometimento organizacional, a fim de favorecer 0 desenvolvimento dos negócios (LEITE et al., 2015).

Segundo Ribeiro e Bastos (2010), as organizações que querem manter-se competitivas ao longo do tempo precisam estimular o comprometimento por parte de seus profissionais, para que os mesmos se tornem mais leais e envolvidos com 0 sucesso da estratégia organizacional e alcance dos resultados almejados.

$\mathrm{Na}$ literatura, são encontrados diferentes antecedentes do comprometimento organizacional, os quais devem ser gerenciados pelas organizações: o compromisso demonstrado pelas chefias, pois os líderes que internalizam e compartilham a visão e valores do negócio influenciam positivamente o comprometimento de seus liderados (ALLEN; ATTOH; GONG, 2017; CHAI; HWANG; JOO, 2017); o clima organizacional, que afeta diretamente o envolvimento do indivíduo em seu ambiente laboral e sua intenção de permanência no emprego (BAHRAMI et al., 2016); e as próprias políticas de gestão de pessoas, que devem propiciar o bem-estar dos funcionários e aumentar sua satisfação no trabalho, impactando de maneira favorável o compromisso deles com o sucesso do negócio (DEMO; MARTINS; ROURE, 2013).

\subsection{Suporte organizacional percebido}

O suporte organizacional percebido refere-se à percepção dos trabalhadores de que seu empregador se preocupa verdadeiramente com seu bem-estar e adota práticas no sentido de valorizá-los e recompensá-los pelas contribuições dadas para o sucesso do negócio (KURTESSIS et al., 2017).

Segundo a Teoria do Apoio Organizacional, a percepção dos indivíduos de que recebem o devido suporte organizacional faz com que eles adotem comportamentos benéficos a seu empregador, e está associada à implantação de políticas de valorização das contribuições individuais no ambiente laboral e, concomitantemente, de práticas que sinalizem genuína preocupação com os trabalhadores e que garantam o bem-estar deles (VARDAMAN et al., 2016).

REUNA, Belo Horizonte - MG, Brasil, v.24, n.3, p. I-19, Jul. - Set. 2019 - ISSN 2179-8834 
O apoio organizacional percebido torna mais positiva a visão que os funcionários nutrem a respeito de seu empregador, o que ocorre devido a um processo de intercâmbio social, que promove/estimula, em retribuição à preocupação e suporte por parte da organização, um maior sentimento de obrigação, confiança e expectativa de que os esforços despendidos nas atividades laborais serão adequadamente reconhecidos e recompensados (KURTESSIS et al., 2017).

A atuação da organização visando suprir as necessidades sócio-emocionais de seus funcionários está relacionada a diversos benefícios, como o aumento da identificação e do comprometimento organizacional, assim como o aumento do interesse no trabalho realizado (KURTESSIS et al., 2017).

Logo, percebe-se que indivíduos que compreendem que a organização cuida de seu bem-estar e valoriza devidamente suas contribuições, retribuem este suporte percebido com maior comprometimento, lealdade e desempenho, o que evidencia a importância de se construir uma relação de reciprocidade entre empregado e empregador (RHOADES; EISENBERGER, 2002).

Além disso, conforme se verifica no estudo de Loi, Hang-Yue e Foley (2006), o suporte organizacional faz com que os funcionários desenvolvam um sentimento de apego a seu empregador, reduzindo sua intenção de abandono do emprego.

Nesta linha, baseando-se no pressuposto de que o suporte organizacional percebido afeta de maneira positiva o comportamento humano no trabalho, definiu-se a segunda hipótese da pesquisa:

H2: O suporte organizacional percebido influencia positivamente o comprometimento organizacional.

Portanto, para evitar a rotatividade de pessoal, os gestores devem garantir que as políticas e práticas organizacionais melhorem a percepção de justiça dos funcionários, assim como a percepção dos mesmos de que a organização se sente responsável por eles e busca valorizá-los (LOI; HANG-YUE; FOLEY, 2006).

De forma complementar, conforme se verifica em Karatape (2013), é importante que os funcionários se sintam apoiados o suficiente pela organização onde trabalham, pois isso faz com que eles não apenas desenvolvam um sentimento positivo de afeto em relação a ela, mas também se mostrem intrinsecamente motivados no ambiente laboral e ainda experimentem baixos níveis de exaustão emocional.

Tais apontamentos corroboram os estudos de Tamayo e Tróccoli (2002), que indicam que existe uma relação inversamente proporcional entre o suporte organizacional percebido e a exaustão emocional dos trabalhadores. Ainda segundo esses mesmos autores, para que os indivíduos se sintam apoiados por seu empregador, é necessário que haja abertura para participação nas diversas decisões, estímulo e reconhecimento das contribuições individuais dadas ao negócio, e também clareza nas políticas que os afetam diretamente.

Tomando como base os autores supramencionados, que associam de forma negativa o suporte organizacional percebido aos níveis de exaustão experimentados pelos indivíduos no trabalho, delimitou-se então a terceira hipótese da pesquisa: 
H3: O suporte organizacional percebido influencia negativamente a exaustão emocional dos profissionais.

Dada a importância do suporte organizacional percebido, Lancaster e Milia (2014) fornecem recomendações a respeito do que as empresas podem fazer para desenvolver essa percepção nos funcionários: disponibilizar programas de desenvolvimento de elevada qualidade; garantir que tais programas estejam alinhados à estratégia do negócio e conteúdo do cargo ocupado; e promover o engajamento da alta administração com o processo de crescimento dos indivíduos no âmbito organizacional.

Complementarmente, Kurtessis et al. (2017) apresentam uma visão mais generalista, não limitada apenas à questão da aprendizagem, acerca das diferentes formas de transmitir aos funcionários que a organização se preocupa com seu bemestar e valoriza suas contribuições, englobando o suporte direto dado pelos líderes a seus liderados, a promoção da equidade, a adoção de práticas capazes de compensar adequadamente os indivíduos pela qualidade dos resultados entregues e 0 oferecimento de condições laborais adequadas.

Analisando conjuntamente as recomendações proposta por Lancaster e Milia (2014) e Kurtessis et al. (2017), percebe-se que existem diferentes aspectos que devem ser gerenciados pelas organizações para desenvolver em seus colaboradores a percepção de que se importam com eles, afetando diferentes dimensões do comportamento dos mesmos no trabalho.

\section{Aspectos metodológicos}

O presente estudo pode ser classificado como descritivo de caráter quantitativo, pois teve como objetivo testar hipóteses e descrever determinados aspectos do comportamento da população de interesse, sendo, para isso, coletados dados numéricos, cuja análise foi efetuada mediante aplicação de técnicas estatísticas (HAIR JUNIOR et al., 2005).

O método de pesquisa adotado foi a survey, que consiste na aplicação de um questionário estruturado autoadministrado a uma amostra retirada da população do estudo. Tal método tem como principais vantagens a possibilidade de conhecer diretamente a realidade investigada, a quantificação, viabilizando a análise estatística dos dados coletados, e a economia e rapidez, uma vez que os custos envolvidos são baixos e é possível obter grande número de dados em um espaço de tempo menor, o que justifica seu emprego (GIL, 2008).

Para elaborar o instrumento de coleta de dados, utilizou-se a escala de Likert, que mede o grau de concordância dos respondentes em relação à cada afirmativa apresentada (GIL, 2008; HAIR JUNIOR et al., 2005). Adotou-se o formato de sete pontos, no qual apenas os extremos são nomeados como "discordo totalmente" e "concordo totalmente".

O questionário foi composto por quatro seções: a primeira incluiu questões demográficas, para caracterização dos respondentes; as outras três incluíram 19 questões, sendo oito para mensurar a exaustão emocional do trabalhador, retiradas 
do Maslash Burnout Inventory (MASLACH; JACKSON, 1986), sete para mensurar o comprometimento organizacional, retiradas do estudo de Karatape (2013), e quatro para mensurar o suporte organizacional percebido, retiradas do estudo de Hayton, Carnabuci e Eisenberger (2012). Todas as questões foram traduzidas para o presente estudo.

A população-alvo da pesquisa incluiu os habitantes das cidades de Mariana e Ouro Preto, ambas localizadas no Estado de Minas Gerais, que estavam empregados no momento da coleta de dados. Para selecionar os indivíduos que iriam compor a amostra, foi utilizada a técnica de amostragem não probabilística por conveniência, na qual a escolha das unidades amostrais baseia-se no critério acessibilidade (GIL, 2008).

O uso da amostragem por conveniência neste trabalho justifica-se com base na impossibilidade de se obter uma relação exaustiva de todos os elementos que compõem a população de interesse e, por conseguinte, na inviabilidade de se escolherem as unidades amostrais de forma aleatória (VIANA, 2011).

O tamanho da amostra foi delimitado de acordo com as diretrizes estabelecidas por Hair Junior et al. (2009) de que se deve manter uma proporção de cinco a 20 vezes o número de variáveis de pesquisa. Como foram utilizadas 19 variáveis para mensurar os três construtos estudados, definiu-se que a amostra deveria conter 285 elementos, mantendo uma proporção de 15 unidades amostrais para cada variável.

A coleta de dados foi operacionalizada mediante a aplicação de questionários impressos, distribuídos na região central das cidades de Mariana e Ouro Preto, onde há maior fluxo de pessoas, e também por meio de questionários eletrônicos, cujo link foi divulgado pelo Facebook e via e-mail para a rede de contatos dos pesquisadores, sendo solicitado que eles, por sua vez, redistribuíssem para seus respectivos contatos.

Para análise dos dados coletados, empregou-se a técnica de Modelagem de Equações Estruturais, que permite o exame das inter-relações presentes em uma série de equações, as quais detalham como diferentes construtos estão associados (HAIR JUNIOR et al., 2009). Para o presente estudo, foram utilizadas duas abordagens: a Análise Fatorial Confirmatória (AFC) e a Análise de Caminhos.

Enquanto a AFC permite agrupar as variáveis originais da pesquisa, denominadas de observadas, em um número menor de varáveis latentes, representando cada construto investigado, a Análise de Caminhos possibilita o exame das relações existentes entre as variáveis latentes criadas (HAIR JUNIOR et al., 2009), que, no caso deste trabalho, representaram os construtos exaustão emocional, comprometimento organizacional e suporte organizacional percebido.

$\mathrm{Na}$ Análise de Caminhos, os construtos exaustão emocional e comprometimento organizacional foram representados por variáveis latentes endógenas, ao passo que o construto suporte organizacional foi representado por uma variável latente exógena. O modelo de caminhos testado, assim como as respectivas hipóteses de pesquisa que lhe deram origem, pode ser visualizado na Figura 1. 
Figura 1 - Modelo de caminhos proposto

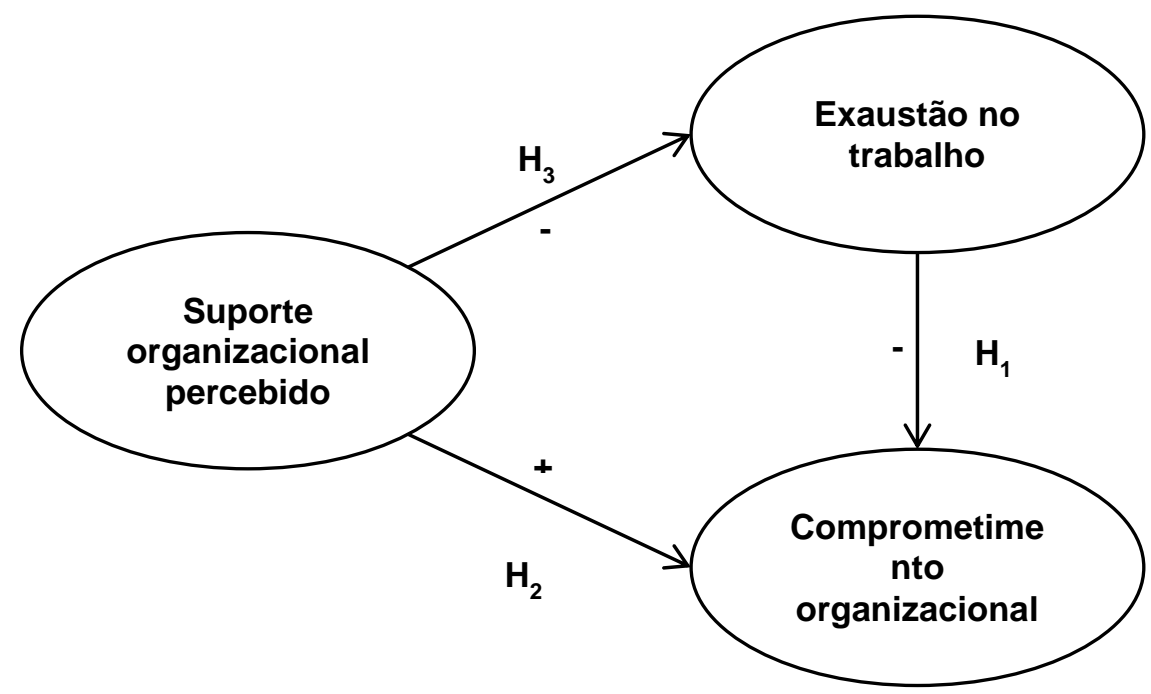

Fonte: dados da pesquisa.

\section{Apresentação e discussão dos resultados}

A amostra coletada foi composta por 309 trabalhadores, sendo $43 \%$ deles do gênero masculino e $57 \%$ do gênero feminino. Com relação à idade, $41,4 \%$ possuem entre 18 e 25 anos; $31,7 \%$, entre 26 e 33 anos; $15,5 \%$, entre 34 e 41 anos; $6,1 \%$, entre 42 e 49 anos; e 4,8\% possuem 50 anos ou mais. Quanto ao estado civil, $69,3 \%$ são solteiros, $24,9 \%$ são casados e $5,8 \%$ apresentam outros estados civis.

Em relação ao número de filhos, $72,5 \%$ dos indivíduos que compuseram a amostra não possuem filhos, $12,9 \%$ possuem apenas um filho; $9,4 \%$, dois filhos; e $5,2 \%$, três ou mais filhos. Por fim, quanto ao grau de escolaridade, $48,5 \%$ possuem ensino superior incompleto; $31,4 \%$, ensino superior completo; $17,1 \%$, ensino médio; e $2,9 \%$, ensino fundamental.

Antes de proceder à Modelagem de Equações Estruturais, avaliou-se a normalidade dos dados. Para isso, foram utilizadas duas medidas: assimetria e curtose. De acordo com Hair Junior et al. (2005), a assimetria de cada variável deve apresentar valores dentro do intervalo de $+1 \mathrm{e}-1$, enquanto a curtose deve ficar entre +3 e -3. Analisando essas duas medidas para cada uma das variáveis da pesquisa, verificou-se que nenhum valor obtido extrapolou os intervalos indicados na literatura, evidenciando que todas apresentam distribuição normal.

Também se analisou a confiabilidade das escalas utilizadas para medir cada construto. Para isso, optou-se pelo Alfa de Cronbach, que deve alcançar, no mínimo, 0,7 para ser considerado aceitável (HAIR JUNIOR et al., 2005). Os Alfas obtidos para os conjuntos de variáveis adotadas para mensurar a exaustão, o comprometimento e o suporte organizacional percebido foram, respectivamente, $0,889,0,893,0,941$, indicando alta consistência interna das escalas empregadas. 
Confirmada a confiabilidade das escalas e a normalidade dos dados, rodou-se no software AMOS um primeiro modelo de equações estruturais, que contou com todas as variáveis observadas originalmente incluídas no estudo. Todavia, foi necessário excluir as variáveis EXAU4 e EXAU6, que apresentaram cargas fatoriais menores do que 0,5, parâmetro mínimo recomendado por Hair Junior et al. (2009). Feitas essas exclusões, um novo modelo foi rodado, conforme se verifica na Figura 2.

Figura 2 - Modelo proposto e respectivos coeficientes padronizados

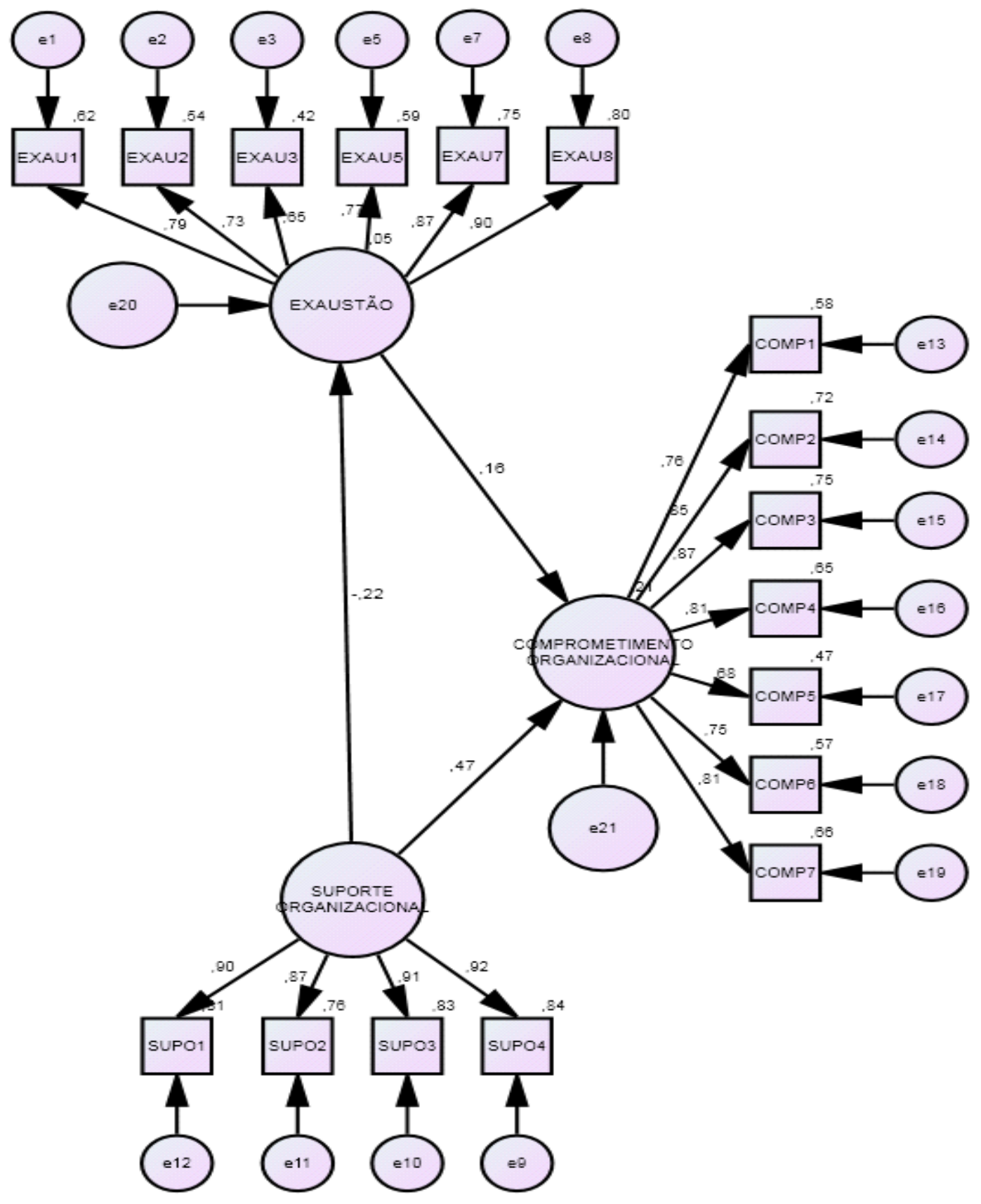

Fonte: Dados da pesquisa analisados por meio do software AMOS. 
Contudo, antes de analisar as novas estimativas obtidas, examinou-se a qualidade do ajuste proporcionado pelo segundo modelo testado. Para isso foram utilizadas as seguintes medidas: qui-quadrado normado (CMIN/DF ou relative chisquare), erro quadrático médio de aproximação (RMSEA ou root mean squase error of approximation), índice de qualidade de ajuste (GFI ou goodness-of-fit-index) e índice de ajuste calibrado (AGFI ou adjusted goodness-of-fit-index).

Para medir a qualidade do ajuste parcimonioso, foi utilizado o qui-quadrado normado, cujo valor deve ser inferior a 5,0 (MARSH; HOCEVAR, 1985). Como o quiquadrado normado encontrado foi de 2,778 , conclui-se que o modelo apresenta bom ajuste parcimonioso.

Por sua vez, a qualidade do ajuste incremental foi avaliada a partir do índice de qualidade de ajuste e do índice de ajuste calibrado. O GFI obtido foi de 0,877, que se aproxima do parâmetro mínimo recomendado por Hair Junior et al. (2009) de 0,9. Já o AGFI foi de 0,838, superando o parâmetro mínimo de 0,8 indicado por Stacciarini e Pace (2017). Analisando os dois valores conjuntamente, verifica-se que o modelo testado apresenta bom ajuste incremental.

Finalmente, a qualidade do ajuste absoluto foi examinada utilizando-se o erro quadrático médio de aproximação, cujo valor deve ser inferior a 0,08 (LOMAX, 2013). Como o RMSEA obtido foi de 0,076, confirma-se que o modelo também apresenta bom ajuste absoluto.

Analisando de forma concomitante as quatro medidas supracitadas, pode-se constatar que o modelo de equações estruturais testado apresenta boa qualidade de ajuste, o que permitiu validá-lo. Sendo assim, procedeu-se ao exame das estimativas obtidas na Análise Fatorial Confirmatória.

Segundo Hair Junior et al. (2009), as cargas fatoriais relativas às relações entre as variáveis observadas e as respectivas variáveis latentes nas quais elas foram agrupadas devem, idealmente, ser superiores a 0,7, sendo, porém, aceitáveis valores acima de 0,5 . No modelo analisado, todas as variáveis alcançaram cargas fatoriais superiores a 0,7, com exceção da variável observada EXAU3, que atingiu o valor de 0,65, também considerado aceitável segundo a literatura.

Em seguida, analisou-se a significância estatística dos agrupamentos propostos, sendo obtidos p-valores inferiores a 0,05 para todas as relações. Logo, confirma-se, adotando um nível de $95 \%$ de confiança, que todas as variáveis observadas apresentaram relação estatisticamente significativa com as respectivas variáveis latentes nas quais foram agrupadas.

Posteriormente, foi calculada a variância extraída (VE), que se refere à carga fatorial quadrática média de cada variável latente. De acordo com Hair Junior et al. (2009), uma VE superior a 0,5 indica convergência adequada. No modelo testado, as variáveis latentes exaustão, comprometimento organizacional e suporte organizacional percebido apresentaram, respectivamente, variâncias extraídas de $0,62,0,81$ e 0,63 .

De forma complementar, calculou-se a confiabilidade de cada construto (CR ou composite reliability), sendo recomendados valores superiores a 0,7 (HAIR JUNIOR et al., 2009). No modelo testado, as variáveis latentes exaustão, comprometimento organizacional e suporte organizacional apresentaram valores para a CR de, respectivamente, 0,91, 0,94 e 0,92. 
Analisando conjuntamente a variância extraída e a confiabilidade do construto, conclui-se que a Análise Fatorial Confirmatória realizada possui validada convergente adequada, o que permite validá-la.

Com isso, ratifica-se a criação das três variáveis latentes que representaram os construtos exaustão, comprometimento e suporte organizacional percebido, compostas, respectivamente, por seis, sete e quatro variáveis observadas, listadas no Quadro 1.

\section{Quadro 1 - Variáveis observadas que originaram as variáveis latentes do modelo}

\begin{tabular}{|c|c|c|}
\hline Exaustão & $\begin{array}{c}\text { Comprometimento } \\
\text { organizacional }\end{array}$ & $\begin{array}{l}\text { Suporte organizacional } \\
\text { percebido }\end{array}$ \\
\hline $\begin{array}{l}\text { EXAU1. Sinto-me } \\
\text { emocionalmente esgotado no } \\
\text { meu trabalho. } \\
\text { EXAU2. Sinto-me cansado ao } \\
\text { final do dia trabalhado. } \\
\text { EXAU3. Sinto-me cansado } \\
\text { quando levanto pela manhã e } \\
\text { tenho que encarar outro dia no } \\
\text { trabalho. } \\
\text { EXAU5. Eu me sinto } \\
\text { exausto devido ao meu } \\
\text { trabalho. } \\
\text { EXAU7. Sinto que estou } \\
\text { trabalhando muito. } \\
\text { EXAU8. Sinto que estou } \\
\text { sobrecarregado. }\end{array}$ & $\begin{array}{l}\text { COMP1. Sinto-me apegado à } \\
\text { minha empresa. } \\
\text { COMP2. Seria difícil para mim } \\
\text { sair desta empresa } \\
\text { COMP3. Estou muito envolvido } \\
\text { nesta empresa para sair. } \\
\text { COMP4. Tenho um vínculo } \\
\text { emocional com esta empresa. } \\
\text { COMP5. Eu simplesmente não } \\
\text { posso deixar a empresa em que } \\
\text { trabalho. } \\
\text { cOMP6. Sinto-me no dever de } \\
\text { permanecer na empresa em que } \\
\text { trabalho. } \\
\text { cOMP7. Estou fortemente } \\
\text { conectado com esta empresa. }\end{array}$ & $\begin{array}{l}\text { SUPO1. A empresa onde } \\
\text { trabalho está disposta a me } \\
\text { ajudar quando preciso de } \\
\text { ajuda. } \\
\text { SUPO2. A empresa onde } \\
\text { trabalho mostra grande } \\
\text { preocupação por mim. } \\
\text { SUPO3. A empresa onde } \\
\text { trabalho valoriza minha } \\
\text { contribuição para o seu bem- } \\
\text { estar. } \\
\text { SUPO4. A empresa onde } \\
\text { trabalho se importa com meus } \\
\text { objetivos e valores. }\end{array}$ \\
\hline
\end{tabular}

Fonte: dados da pesquisa.

Em seguida, procedeu-se ao exame das estimativas e coeficientes beta obtidos nas relações testadas por meio da Análise de Caminhos, iniciando-se pela influência do suporte organizacional percebido sobre a exaustão. Adotando um nível de confiança de 95\%, confirmou-se que tal relação possui significância estatística, considerando que o p-valor foi de 0,002. Como o beta encontrado foi de $-0,218$, verifica-se que os dois construtos se associam de forma inversamente proporcional, ou seja, quando há um aumento no suporte organizacional percebido pelo trabalhador, reduz-se a exaustão experimentada por ele. Com isso, ratifica-se $\mathrm{H}_{3}$.

A segunda relação testada remete ao impacto do suporte organizacional percebido sobre o comprometimento organizacional. $O \mathrm{p}$-valor obtido foi de 0,000 , confirmando a significância estatística desta relação. O beta calculado foi de 0,468 , indicando que os construtos se relacionam de maneira diretamente proporcional, ou seja, quando há aumento do suporte organizacional percebido, aumenta-se o compromisso do funcionário. Desta forma, confirma-se $\mathrm{H}_{2}$. 
Por fim, para a relação entre exaustão e comprometimento organizacional, o pvalor obtido foi de 0,012, evidenciando sua significância estatística. $O$ valor do coeficiente beta foi de 0,161 , indicando uma relação diretamente proporcional. Logo, o aumento na exaustão refletiu positivamente no comprometimento organizacional dos indivíduos que fizeram parte da amostra do estudo, o que leva à rejeição de $\mathrm{H}_{1}$.

A relação negativa entre o suporte organizacional percebido e a exaustão é confirmada pelos estudos de Shantz et al. (2016), que constataram que o suporte dado aos trabalhadores implica um menor nível de esgotamento individual nas atividades laborais. De maneira complementar, nos achados de Tamayo e Tróccoli (2002), foi observado que o aumento do suporte organizacional percebido reduz a exaustão emocional experimentada pelos indivíduos em suas atividades profissionais.

Por sua vez, a relação positiva entre o suporte organizacional percebido e o comprometimento organizacional encontra respaldo no estudo de Rhoades e Eisenberger (2002), que indica que os indivíduos que percebem maior apoio da organização onde trabalham respondem com maior compromisso. Da mesma forma, Loi, Hang-Yue e Foley (2006) apontam que o suporte por parte da organização leva ao desenvolvimento de uma forte ligação entre ela e seus funcionários.

Por fim, a relação positiva entre a exaustão e o comprometimento obtida na presente pesquisa ainda carece de estudos na literatura, não sendo encontrados subsídios que a corroborem. Todavia, conforme se verifica em Karatepe (2013), a exaustão, que pode ser originada devido ao excesso de trabalho e/ou aos conflitos existentes entre as dimensões da vida do trabalhador, tende a levar a um afastamento do ambiente laboral. Seguindo essa linha, o resultado encontrado vai de encontro à escassa literatura sobre 0 assunto.

Entretanto, uma hipótese que explica a relação positiva entre a exaustão do trabalhador e o comprometimento organizacional remete a um cenário em que o esgotamento mental, alcançado em decorrência da sobrecarga de atividades, leva a uma percepção por parte do profissional de que a organização tem uma dívida com ele e deveria compensá-lo por desgaste tão severo, passando a nutrir uma expectativa de que será reconhecido/recompensado por isso no futuro.

A partir dessa hipótese, que precisa ser testada em estudos futuros, verifica-se que, de forma complementar ao que indica a literatura que trata do tema comprometimento organizacional, algumas vezes o indivíduo não permanece na organização porque sente que tem uma dívida com ela, mas por considerar que ela tem uma dívida com ele e vai lhe recompensar futuramente.

\section{Considerações finais}

À medida que se ampliou a importância atribuída às pessoas no meio organizacional, temáticas ligadas ao comportamento humano no trabalho passaram a receber maior atenção de gestores e pesquisadores. Nesta linha de investigação, contudo, ainda carece de estudos o impacto que o suporte recebido do empregador exerce sobre o trabalhador.

Sendo assim, delimitou-se como objetivo da presente pesquisa analisar a influência que o suporte organizacional percebido exerce sobre o nível de exaustão emocional e o comprometimento organizacional dos trabalhadores. 
Após a análise dos dados coletados, concluiu-se, com respaldo da literatura consultada, que, quando a organização, por meio de práticas específicas, sinaliza a seus funcionários que se preocupa com seu bem-estar e reconhece sua contribuição para o sucesso dos negócios, amplia-se o comprometimento organizacional e, ao mesmo tempo, reduz-se a exaustão emocional experimentada pelos indivíduos em suas atividades laborais.

Desta forma, é possível confirmar a importância dos programas de treinamento e desenvolvimento, da capacitação dos líderes da organização, da promoção da justiça organizacional, das ações voltadas à oferta de condições laborais adequadas e dos sistemas de remuneração que sejam capazes de recompensar os indivíduos pelos resultados entregues, elementos apontados na literatura como capazes de estimular nos trabalhadores a percepção de que são valorizados por seus empregadores.

Evidencia-se, portanto, que a reciprocidade deve ser princípio-chave na relação entre as organizações e seus respectivos colaboradores, trazendo ganhos para ambos, pois leva os indivíduos a experimentarem menor esgotamento no trabalho e, ao mesmo tempo, a apresentarem maior compromisso com seu empregador.

Adicionalmente, também se observou, entre os resultados obtidos, uma relação positiva entre a exaustão emocional e o comprometimento organizacional dos profissionais, que se mostrou conflitante com a escassa literatura sobre o tema. Uma possível explicação para tal achado é que o indivíduo pode alcançar o esgotamento de seus recursos mentais devido ao excesso de trabalho e, nessas circunstâncias, apegar-se à organização, na esperança de que ela reconheça e recompense sua dedicação futuramente.

Neste sentido, sugere-se que estudos futuros explorem esse possível vínculo entre organização e funcionários pautado na expectativa de reconhecimento posterior alimentada pelo trabalhador como uma forma de retribuição pelo desgaste experimentado por ele em prol de seu empregador.

Ademais, pode-se apontar como sugestão para novos estudos que seja testada a relação entre o suporte organizacional percebido e outras dimensões do comportamento humano no trabalho, como o engajamento e a identificação organizacional, permitindo que se avance na compreensão de como a reciprocidade percebida pelos trabalhadores afeta diferentes dimensões de seu comportamento no âmbito das organizações.

Para finalizar, aponta-se como contribuição gerencial deste estudo a identificação de alguns benefícios para as organizações, caso adotem práticas capazes de promover nos funcionários uma percepção de que são respeitados e valorizados enquanto seres humanos, reforçando a importância da reciprocidade entre empregados e empregadores. Já a contribuição acadêmica que pode ser atribuída a esta pesquisa reside no subsídio que fornece para reduzir uma lacuna nos estudos ligados ao comportamento dos indivíduos no universo do trabalho, especificamente no que se refere aos reflexos do suporte organizacional. 


\section{Referências}

ALLEN, G. W.; ATTOH, P. A.; GONG, T. Transformational leadership and affective organizational commitment: mediating roles of perceived social responsibility and organizational identification. Social Responsibility Journal, v. 13, n. 3, p. 585-600, 2017.

BAHRAMI, M. A.; BARATI, O.; GHOROGHCHIAN, M. S.; MONTAZER-ALFARAJ, R.; EZZATABADI, M. R. Role of organizational climate in organizational commitment: the case of teaching hospitals. Osong Public Health and Research Perspectives, v. 7, n. 2, p. 96-100, 2016.

BIANCHI, E. M. P. G.; QUISHIDA, A.; FORONI, P. G. Atuação do líder na gestão estratégica de pessoas: reflexões, lacunas e oportunidades. Revista de Administração Contemporânea, v. 21, n. 1, p. 41-61, 2017.

BORGES-ANDRADE, J. E. Conceituação e mensuração de comprometimento organizacional. Temas em Psicologia, v. 2, n. 1, p. 37-47, 1994.

BRITO, A. P. M. P.; BASTOS, A. V. B. O Schema de 'trabalhador comprometido' e gestão do comprometimento: um estudo entre gestores de uma organização petroquímica. Organizações e Sociedade, v. 8, n. 22, p. 1-24, 2001.

CHAI, D. S.; HWANG, S. J.; JOO, B. K. Transformational leadership and organizational commitment in teams: the mediating roles of shared vision and team goal commitment. Performance Improvement Quarterly, v. 30, n. 2, p. 137-158, 2017.

CHI, S. C. S.; LIANG, S. G. When do subordinates' emotion-regulation strategies matter? Abusive supervision, subordinates' emotional exhaustion, and work withdrawal. The Leadership Quarterly, v. 24, n. 1, p. 125-137, 2013.

CHO, J. E.; CHOI, H. S. C.; LEE, W. J. An empirical investigation of the relationship between role stressors, emotional exhaustion and turnover intention in the airline industry. Asia Pacific Journal of Tourism Research, v. 19, n. 9, p. 1023-1043, 2014.

CORDES, C. L.; DOUGHERTY, T. W. A review and an integration of research on job burnout. Academy of Management Review, v. 18, n. 4, p. 621-656, 1993.

DEMO, G.; MARTINS, P. R.; ROURE, P. Políticas de gestão de pessoas, comprometimento organizacional e satisfação no trabalho na Livraria Cultura. Revista Alcance, v. 20, n. 2, p. 237-254, 2013.

GIL, A. C. Métodos e técnicas de pesquisa social. 6. ed. São Paulo: Atlas, 2008.

HAIR JUNIOR, J. F.; BABIN, B.; MONEY, A. H.; SAMOUEL, P. Fundamentos de métodos de pesquisa em Administração. Porto Alegre: Bookman, 2005.

HAIR JUNIOR, J. F.; BLACK, W. C.; BABIN, B. J.; ANDERSON, R. E.; TATHAM, R. L. Análise multivariada de dados. 6. ed. Porto Alegre: Bookman, 2009. 
HAYTON, J. C.; CARNABUCI, G.; EISENBERGER, R. With a little help from my colleagues: A social embeddedness approach to perceived organizational support. Journal of Organizational Behavior, v. 33, n. 2, p. 235-249, 2012.

KARATEPE, O. M. The effects of work overload and work-family conflict on job embeddedness and job performance: the mediation of emotional exhaustion. International Journal of Contemporary Hospitality Management, v. 25, n. 4, p. 614-634, 2013.

KURTESSIS, J. N.; EISENBERGER, R.; FORD, M. T.; BUFFARDI, L. C.; STEWART, K. A.; ADIS, C. S. Perceived organizational support: a meta-analytic evaluation of organizational support theory. Journal of Management, v. 43, n. 6, p. 1854-1884, 2017.

LANCASTER, S.; MILIA, L. Organisational support for employee learning: an employee perspective. European Journal of Training and Development, v. 38, n. 7, p. 642-657, 2014.

LEITE, A. M. A. A.; FERREIRA FILHO, J.; CABRAL, A. C. A.; SANTOS, S. M.; PESSOA, M. N. M. Visão compartilhada e comprometimento organizacional: um estudo de caso na Embracon - empresa brasileira de consórcios. Revista de Administração da UFSM, v. 8, n. 3, p. 482-498, 2015.

LLOYD, K. J.; BOER, D.; KELLER, J. W.; VOELPEL, S. Is my boss really listening to me? The impact of perceived supervisor listening on emotional exhaustion, turnover intention, and organizational citizenship behavior. Journal of Business Ethics, v. 130, n. 3, p. 509-524, 2015.

LOI, R.; HANG- YUE, N.; FOLEY, S. Linking employees' justice perceptions to organizational commitment and intention to leave: the mediating role of perceived organizational support. Journal of Occupational and Organizational Psychology, v. 79, n. 1, p. 101-120, 2006.

LOMAX, R. Introduction to structural equation modeling. In: PETSCHER, Y.; SCHATSCHNEIDER, C.; COMPTON, D. L. Applied quantitative analysis in education and the social sciences. New York: Routledge, 2013.

LU, C. Q.; SUN, J. W.; DU, D. Y. The relationships between employability, emotional exhaustion, and turnover intention: the moderation of perceived career opportunity. Journal of Career Development, v. 43, n. 1, p. 37-51, 2016.

MARSH, H. W.; HOCEVAR, D. Application of confirmatory factor analysis to the study of self-concept: first-and higher order factor models and their invariance across groups. Psychological Bulletin, v. 97, n. 3, p. 562-582, 1985.

MASLACH, C.; GOLDBERG, J. Prevention of burnout: new perspectives. Applied and Preventive Psychology, v. 7, n. 1, p. 63-74, 1998.

MASLACH, C.; JACKSON, S. E. Maslach Burnout Inventory. Palo Alto: Consulting Psychologist Press, 1986. 
MEYER, J. P.; ALLEN, N. J. A three-component conceptualization of organizational commitment. Human Resource Management Review, v. 1, n. 1, p. 61-89, 1991.

MEYER, J. P.; ALLEN, N. J.; SMITH, C. A. Commitment to organizations and occupations: extension and test of a three-component conceptualization. Journal of Applied Psychology, v. 78, n. 4, p. 538-551, 1993.

OLIVEIRA, P. M.; LIMONGI-FRANÇA, A. C. Avaliação da gestão de programas de qualidade de vida no trabalho. RAE-Eletrônica, v. 4, n. 1, p. 1-21, 2005.

OSTERMAN, P. Institutional labor economics, the new personnel economics, and internallabor markets: a reconsideration. Industrial and Labor Relations Review, v. 64, n. 4, p. 637-653, 2011.

PAIVA, L. E. B.; LIMA, T. C. B.; SOUZA, I. C. S.; PITOMBEIRA, S. S. R.; ARRUDA, S. C. Síndrome de burnout em operadores de teleatendimento: o caso de duas empresas de contact center em Fortaleza/CE . Revista de Carreiras e Pessoas, v. 6, n. 2, p. 216-233, 2016.

PASCHOAL, T.; TORRES, C. V.; PORTO, J. B. Felicidade no trabalho: relações com suporte organizacional e suporte social. Revista de Administração Contemporânea, v.14, n. 6, p. 1054-1072, 2010.

RHOADES, L.; EISENBERGER, R. Perceived organizational support: a review of the literature. Journal of Applied Psychology, v. 87, n. 4, p. 698-714, 2002.

RIBEIRO, J. A.; BASTOS, A. V. B. Comprometimento e justiça organizacional: um estudo de suas relações com recompensas assimétricas. Psicologia: Ciência e Profissão, v. 30, n. 1, p. 4-21, 2010.

RODRIGUES, A. C. A.; BASTOS, A. V. B. Problemas conceituais e empíricos na pesquisa sobre comprometimento organizacional: uma análise crítica do modelo tridimensional de J. Meyer e N. Allen. Revista Psicologia: Organizações e Trabalho, v. 10, n. 2, p. 129-144, 2010.

ROŽMAN, M.; TREVEN, S.; ČANČER, V.; CINGULA, M. Burnout of older and younger employees-the case of Slovenia. Organizacija, v. 50, n. 1, p. 47-62, 2017.

SCHERMULY, C.C.; MEYER, B. Good relationships at work: the effects of leadermember exchange and team-member exchange on psychological empowerment, emotional exhaustion, and depression. Journal of Organizational Behavior, v. 37, n. 5, p. 673-691, 2016.

SHANTZ, A.; AREVSHATIAN, L.; ALFES, K.; BAILEY, C. The effect of HRM attributions on emotional exhaustion and the mediating roles of job involvement and work overload. Human Resource Management Journal, v. 26, n. 2, p. 172-191, 2016.

SILVA, J. C. R.; VIEIRA, E. T.; RODRIGUES, J. L. K. Comprometimento organizacional: estudo de caso em uma instituição financeira em processo de integração no Vale do Paraíba Paulista. Revista Gestão.Org, v. 12, n. 2, p. 173-184, 2014. 
STACCIARINI, T. S. G.; PACE, A. E. Análise fatorial confirmatória da escala Appraisal of Self Care Agency Scale - Revised. Revista Latino-Americana de Enfermagem, v. 25, p. 1-9, 2017.

TAMAYO, A. Exaustão emocional no trabalho. Revista de Administração, v. 37, n. 2, p. 26-37, 2002.

TAMAYO, M. R.; TRÓCCOLI, B. T. Exaustão emocional: relações com a percepção de suporte organizacional e com as estratégias de coping no trabalho. Estudos de Psicologia, v. 7, n. 1, p. 37-46, 2002.

VARDAMAN, J. M.; ALLEN, D. G.; OTONDO, R. F.; HANCOCK, J. I.; SHORE, L. M.; ROGERS, B. L. Social comparisons and organizational support: implications for commitment and retention. Human Relations, v. 69, n. 7, p. 1483-1505, 2016.

VIANA, A. B. N. Pesquisa quantitativa aplicada ao varejo. In: MERLO, E. M. (Org.). Administração de varejo com foco em casos brasileiros. Rio de Janeiro: LTC, 2011.

WHEELER, A. R.; HALBESLEBEN, J. R. B.; WHITMAN, M. V. The interactive effects of abusive supervision and entitlement on emotional exhaustion and coworker abuse. Journal of Occupational and Organizational Psychology, v. 86, n. 4, p. 477496, 2013.

WIJNMAALEN, J.; HEYSE, L.; VOORDIJK, H. Organisational commitment and turnover intentions in humanitarian organisations. International Journal of Human Resources Development and Management, v. 16, n. 1-2, p. 47-66, 2016. 